Review

\title{
The Role of Cyclophilins in Inflammatory Bowel Disease and Colorectal Cancer
}

\author{
Lifang Liang1, Rongxiao Lin², Ying Xie², Huaqing Lin²,3,4, Fangyuan Shao7, Wen Rui ${ }^{2,4,5,6 \bowtie}$ and Hongyuan \\ Chen ${ }^{1,3,4,5,6 \times}$ \\ 1. Department of Pathogenic Biology and Immunology, School of Life Sciences and Biopharmaceuticals, Guangdong Pharmaceutical University, Guangzhou \\ 510006, Guangdong Province, PR China. \\ 2. Centrefor Novel Drug Research and Development, Guangdong Pharmaceutical University, Guangzhou 510006, Guangdong Province, PR China. \\ 3. GDPU-HKU Zhongshan Biomedical Innovation Plaform, Zhongshan 528437, Guangdong Province, PR China. \\ 4. Guangdong Engineering \& Technology Research Center of Topical Precise Drug Delivery System, Guangdong Pharmaceutical University, Guangzhou \\ 510006, Guangdong Province, PR China. \\ 5. Key Laboratory of Digital Quality Evaluation of Chinese Materia Medica of State Administration of TCM, Guangzhou 510006, Guangdong Province, PR \\ China. \\ 6. Guangdong Cosmetics Engineering \& Technology Research Center,Guangzhou 510006, Guangdong Province, PR China. \\ 7. Cancer Center, Faculty of Health Sciences, University of Macau, Macau SAR, China. \\ $\square$ Corresponding authors: Hong-Yuan Chen, E-mail: hychen@gdpu.edu.cn, Tel \& Fax: +86-20-3935-2186. Wen Rui, E-mail: gyrw@gdpu.edu.cn, Tel \& Fax: \\ $+86-20-3935-2527$
}

(1) The author(s). This is an open access article distributed under the terms of the Creative Commons Attribution License (https://creativecommons.org/licenses/by/4.0/). See http://ivyspring.com/terms for full terms and conditions.

Received: 2021.01.26; Accepted: 2021.05.04; Published: 2021.06.16

\begin{abstract}
Cyclophilins (Cyps) is a kind of ubiquitous protein family in organisms, which has biological functions such as promoting intracellular protein folding and participating in the pathological processes of inflammation and tumor. Inflammatory bowel disease (IBD) and colorectal cancer (CRC) are two common intestinal diseases, but the etiology and pathogenesis of these two diseases are still unclear. IBD and CRC are closely associated, IBD has always been considered as one of the main risks of CRC. However, the role of Cyps in these two related intestinal diseases is rarely studied and reported. In this review, the expression of CypA, CypB and CypD in IBD, especially ulcerative colitis (UC), and CRC, their relationship with the development of these two intestinal diseases, as well as the possible pathogenesis, were briefly summarized, so as to provide modest reference for clinical researches and treatments in future.
\end{abstract}

Key words: inflammatory bowel disease; colorectal cancer; cyclophilins; CypA; CypB; CypD

\section{Introduction}

Cyps, a highly conserved protein family, is ubiquitous in prokaryotic and eukaryotic organisms. [1]. This family generally possesses the activity of peptidyl prolyl cis-trans isomerase (PPIase), which be able to catalyze the cis-trans isomerization of proline residue peptide bonds. Indeed, due to the PPIase activity, Cyps has been demonstrated to play a role in protein folding $[2,3]$, and protein trafficking as well as chaperone activity $[3,4]$. Through this characteristic, on the one hand, Cyps exerts immunosuppressive effects. Cyps inhibits the activity of calcineurin through the interaction with cyclosporin A (CsA), and immunosuppressive drugs, via theirs PPIase active site, blocking the translocation of the nuclear factor of activated $\mathrm{T}$ cells (NF-AT) from the cytosol to the nucleus, and thus preventing the activation of $\mathrm{T}$ cells [5]. On the other hand, Cyps inhibits cell proliferation and differentiation, promote apoptosis, etc. [6, 7]. In addition, Cyps has also known to have relationship with the pathological processes of many diseases, such as viral infection [8,9], cardiovascular diseases [10], inflammatory responses [11, 12] and cancers [13].

Up till now, there are at least 16 known human Cyps, which are structurally distinct [14], including Cyclophilin A (CypA), Cyclophilin B (СурB), Cyclophilin C (CypC), Cyclophilin D (CypD), Cyclophilin 40 (Cyp40), Cyclophilin NK (CypNK) etc. [15]. Among them, most of the studies mainly focused 
on CypA, CypB and CypD. These members are found ubiquitously in different subcellular compartments. They have their own unique biological functions in cells consequently.

CypA, expressed in the cytosol, is the most abundantly expressed and first identified cyclophilin [16]. Substantial evidence showed that intracellular CypA (iCypA) is secreted by several cell types, including vascular smooth muscle cells (VSMC), macrophages, and endothelial cells (EC), in response to inflammatory stimuli [17-24]. Apart from the ordinary functions of Cyps, secreted CypA or named extracellular CypA (eCypA) participates in both inflammatory response and signal transduction [12, 23, 25]. Additionally, the eCypA, through autocrine and paracrine, can mediate intercellular communications, serving as a chemokine that recruit inflammatory cells, as well as aggravate oxidative stress and inflammation [26, 27]. Furthermore, studies suggested that high CypA expression correlates with poor outcome in patients with inflammatory diseases [20]. Meanwhile, various reports have shown that CypA is upregulated in cancer [28-33] and is involved in diverse pathological processes of cancer development, such as synthesis of tumor-associated proteins, signal transmission of tumor cell growth, regulation of transcription factors, apoptosis, metastasis, and drug resistance [13, 16, 34-36]. However, it is worth mentioning that a number of mechanistic details about CypA in IBD and CRC are still unknown and await further studies.

CypB is mainly located in the endoplasmic reticulum (ER), where it attenuates ER stress-induced cell injury by interacting with the ER-related chaperones [37]. Cystolic CypB can also be stimulated by inflammation to form extracellular CypB (eCypB) [38-40]. еСурB has multiple functions, including chemotaxis and signaling transduction [41-47]. In addition, СурB is closely associated with the replication of hepatitis virus [48-52] and human immunodeficiency virus (HIV) [53], and found high expression in breast cancer, pancreatic cancer, glioblastoma, liver cancer and gastric cancer [54-59].

CypD, a component of the mitochondrial permeability transition pore $(\mathrm{mPTP})$, is uniquely located in the mitochondrial matrix. It is responsible for regulating the opening of the MPTP [60]. MPTP is a mitochondrial channel complex, primarily composed by several proteins, including voltage-dependent anion channel (VDAC), adenine nucleotide translocator-1 (ANT-1), and CypD [61], whose main function is to maintain the balance of mitochondrial respiratory chain [62]. Under resting conditions, CypD shuts down the channel complex [62-64]. When facing stimuli of hypoxia, calcium overload, and oxidative stress, CypD travels to the inner membrane and binds to ANT-1, which leads to mPTP sustained opening [63, 65-68], followed by mitochondrial membrane depolarization, mitochondria swelling, $\mathrm{Ca}^{2+}$ release, and eventually, cell death [62, 69-71]. CypD is the basic component of mitochondrial function, and may contribute to regulating the opening state of $\mathrm{MPTP}$ to regulate inflammation [72] and cancer [73].

IBD has emerged as global diseases [74-80]. New data suggest that the incidence and prevalence of IBD are affecting five million patients worldwide, and approximately $0.3 \%$ of the European and North American population suffer from IBD at the present time [79, 81, 82]. IBD is a group of chronic, characterized by macrophages and neutrophils infiltration. Primarily, there are two clinical types of IBD: UC and Crohn's disease (CD) [83-88].

$\mathrm{UC}$, the most common type of IBD, occurs mostly in the colon, affecting the entire intestinal tract in a discontinuous manner $[89,90]$. $C D$, on the other hand, mainly occurs in the rectum and affects part or all of the colon in a continuous manner [91, 92]. According to statistics, in the countries with the highest incidence of IBD, the annual incidence of UC and CD was 24.3 and 12.7 per 100,000 person-years in Europe, 6.3 and 5 per 100,000 person-years in Asia and the Middle East, and 19.2 and 20.2 per 100,000 person-years in North America [81, 93, 94]. The overall incidence is coalescing around a range between 15 and 5 per 100,000 person years for both UC and CD [94]. It can be seen that as two of most common types of IBD diseases, the prevalence and incidence of $\mathrm{UC}$ and $\mathrm{CD}$ are rapidly increasing in the world. Although the researches on IBD have been growing and deepening in recent years, the exact etiology and pathogenesis remain unclear, which brings certain difficulties for clinical researches and disease treatments.

Clinical studies have shown that both UC and $\mathrm{CD}$ patients are at an increased risk for developing CRC compared with the general population $[79,95$, 96]. Furthermore, IBD can eventually develop into intestinal malignant tumor through intestinal adenoma by inducing oncogene instability, oncogene activation, and regulating cell proliferation. [97-100]. $\mathrm{CRC}$ is a common malignant tumor of the digestive tract. Its incidence is increasing every year, with affecting approximately 1.23 million patients worldwide each year and accounting for almost $10 \%$ of all cancers [101-103]. According to statistics, from 2015 to 2020, CRC became one of the leading causes of cancer deaths in China, ranking firmly in the top five cancer-related deaths [104]. Its occurrence and development are affected by many factors, among 
which is closely related to inflammation and damage. Surgery is still the most effective treatment of CRC. Although great progress has been made in the prevention and treatment of tumors, its morbidity and mortality are still high [105]. The main reason is that the disease has tumor features, such as invasion, metastasis, resistance and recurrence and other characteristics [106].

IBD and CRC are currently two of the common diseases in the intestinal tract, they are related but different. In the pathological development of two diseases, IBD can be regarded as one of the main causes of CRC, but they are different in disease characteristics, so this article will discuss the two diseases separately. In a number of studies, it has been found that CRC [107-109] and IBD [110-112] patients generally have high expression of Cyps. The previous research of our group shown that the lack of Cyclophilin J (CypJ) caused the loss of its protective effect in mouse colitis induced by dextransulfatesodium (DSS), and this is related to the ability of CypJ blocking the binding of ubiquitin chains, thereby negatively regulating nuclear factor kappa B (NF-kB) signaling [113]. More relevant experiments are still needed to confirm the role of Cyps in enteritis and bowel cancer.

This article mainly review the expression of Cyps in IBD and CRC, as well as the possible mechanisms related to the occurrence and development of these two diseases, aiming to provide clues for finding an accurate and detectable biomarker for the diagnosis of the diseases.

\section{The relationship between Cyps and inflammatory bowel disease \\ CypA}

It was found that the expression of CypA was significantly increased in the crypt tissue [114], serum [110] and lymphocytes [111] of UC patients. Compared with the concentration of $2 \mathrm{ng} / \mathrm{ml}$ in the serum of health subjects, the CypA level in the serum of UC patients reached $6 \mathrm{ng} / \mathrm{ml}$ [110]. Furthermore, CypA also showed characteristics related to UC disease progression. Expression of CypA in active UC patients was higher than that in remission UC patients [111]. However, studies have further shown that CypA was not significantly elevated in colon tissue of UC patients, nor in serum of CD patients [110]. This indicates that CypA plays an important role in IBD, especially in UC, but it is worth mentioning that the expression level of CypA may be different at different detection levels in UC patients. Simultaneously, in addition to the increase of CypA, the serum antiCypA antibody in UC patients was also increased, and the expression level increased with the course of disease [111, 112], illustrating that the expression level of anti-CypA antibody may be positively correlated with the increase of CypA level, which suggests that anti-CypA also has a certain preoperative diagnostic value in inflammatory enteritis.

Early studies found that eCypA was produced in macrophages stimulated by lipopolysaccharide (LPS) [18] (Figure 1), and it was found to be one of the stable reference genes for evaluating LPS-stimulated macrophages [14]. Additionally, eCypA also upregulated and bound to macrophage surface differentiation cluster 147 (CD147) [115]. In addition, eCypA induced the expression of inflammatory factors such as matrix metalloproteinase 9 (MMP-9), MMP-2, tissue inhibitor of MMP-1 (TIMP-1) [115, 116] or IL-1 $\beta$, IL-6, IL-17 [117, 118] through phosphorylation of (ERK1/2/JNK/P38) MAPK and NF-кB [117, 118], or induced autophagy [119, 120], apoptosis [120], M1 polarization [118], infiltration [12], chemotaxis and adhesion [121, 122] of monocytes/macrophages through these signals, which play a role in various inflammatory diseases (Figure 1). Others speculated that eCypA-induced autophagy in macrophages may be related to PI3K/Akt/mTOR signaling pathway, but no experimental study has been confirmed [95]. However, it is noteworthy that some research results have proved that iCypA promoted the migration of dendritic cells [123] and the proliferation of macrophages [124] by inducing (ERK1/2) MAPK and NF-kB phosphorylation (Figure 1). This opposite effect of eCypA and iCypA on macrophages indicates that different forms of CypA may have opposite biological significance to the same cell by activating the same signal.

Not only macrophages, some researchers speculated that CypA is related to the obvious activation of lymphocytes in patients with $\mathrm{UC}$, and the increase of CypA after lymphocytes activation may participate in the apoptosis of UC [111]. Clinical studies showed that the levels of MMP-9 and TNF-a in UC patients were significantly increased with the increase of serum CypA, and the level of TIMP-1/MMP-9 complex in UC and CD patients were also significantly increased [110], suggesting serum CypA may influence MMPs and TIMPs in IBD patients. This result is consistent with the previous discoveries [115, 121, 122], speculating that the high expression of serum CypA in IBD may regulate the expression of TIMP-1/MMP-9 by activating ERK1/2, which promotes the pathogenesis and development of IBD, expecially UC (Figure 1). Further research is needed to confirm this hypothesis. In short, the difference between eCypA and iCypA lies in that the 
former may need to combine with the receptor CD147 and act on it first. Both receptor-mediated eCypA and iCypA, seems to activate MAPK, NF-kB and other signals to promote the proliferation or apoptosis, migration of a variety of immune cells and the expression of TIMP1, MMP9, MMP2, which may regulate IBD and other inflammatory diseases, but the specific mechanism is still unclear.

CD147, also known as extracellular matrix metalloproteinase inducer (EMMPRIN) or Basigin, is a transmembrane glycoprotein that can induce extracellular MMPs [125, 126]. As matrix metalloproteinases, MMPs have been widely studied in the migration of inflammatory cells, cancer invasion and metastasis due to their universal function of degrading extracellular matrix components $[121,127,128]$. In addition, CD147 is the cell surface receptor of eСypA and еСурB [121, 125, 129, 130]. Heparans may be involved in the signal transduction induced by the binding of these two types of cyclophilins with CD147. It appears plausible that different heparan subtypes on the cell surface, namely sulfated glycosaminoglycans (GAG) and heparan sulfates (HPS, a subtype of GAG), which might facilitate eCypB-CD147 and eCypA-CD147 interaction by first binding eСypB and eCypA, respectively, then presenting them to CD147 (Figure 1) $[131,132]$. The interaction of eCypA-CD147/ eCypB-CD147 and the transfer of eCypA/eCypB into the cells are promoted by the transduction activity of proline 180 (180Pro) and glycine 181 (181Gly) in the extracellular region of CD147, thereby activating the ERK signaling cascade [121, 125, 129, 130] (Figure 1).

Up till now, the importance of CD147 has been generally recognized by researchers $[121,125,129$, 130]. In inflammatory, CD147 mediated the migration of monocytes/macrophages after binding to eCypA [121, 122] (Figure 1). In cancer, CD147 interacted with a variety of proteins, induces the secretion of MMPs, and promoted tumor invasion and metastasis [129, 133-136]. Recent studies have shown that CD147 was significantly increased in intestinal mucosa of IBD patients and aggravated IBD inflammatory response by activating NF-kB [137]. This indicates the important significance of CD147 in inflammatory diseases, and further confirms the results of previous studies [116-124] that eCypA firstly bound to CD147 on cell surface, and activated multiple signal pathways to regulate inflammatory cells, then promoted the expression of MMPs and other factors that can promote the occurrence and development of inflammation such as IBD, expecially UC.

Since the binding of CsA with CypA can inhibit its PPIase activity and exert immunosuppressive effect, it may have adverse effects on the normal immune function or disease treatment of the body [138-141]. Therefore, a variety of CsA analogues binding to Cyps without causing immunosuppression

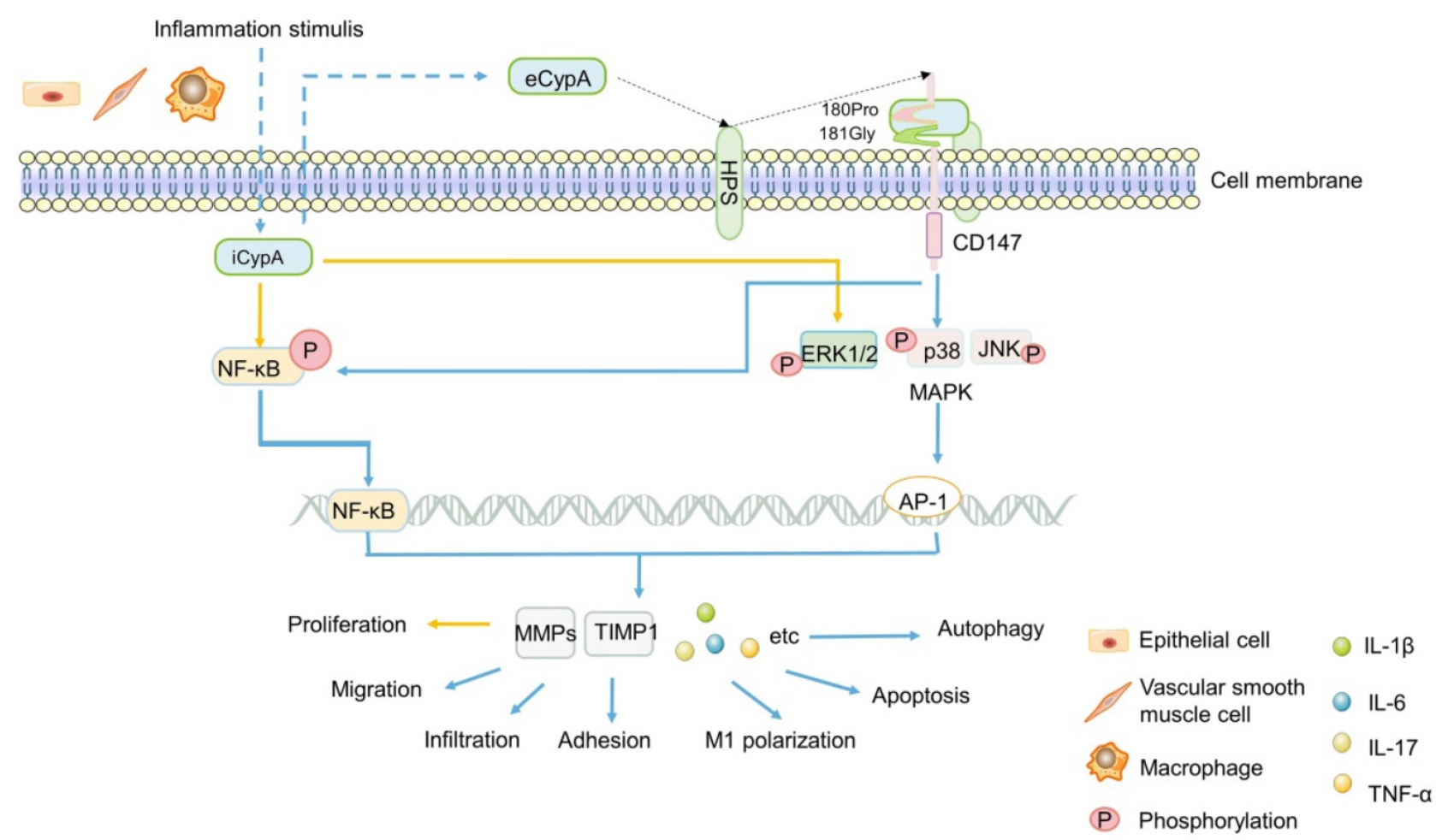

Figure 1. A summary diagram of the possible mechanism of CypA in IBD. Inflammation stimulates a variety of cells to secrete iCypA to form eCypA. The eCypA is presented to CD147 by HPS binding and entering into cells by CD147. Both eCyPA and iCyPA can regulate a variety of factors through NF-kB and MAPK pathways, and exert biological functions on immune cells regulating IBD. 
have been developed clinically [142-146]. In recent years, the researches on CypA have focused on the application of antibodies to diseases. Recombinant purified CypA proteins from different sources [117, 147] were used as immunogens to prepare polyclonal antibodies for the treatment of inflammatory diseases such as acute pneumonia [117] and sepsis [147]. However, the application of anti-CypA antibodies in the treatment of IBD has not been found so far, which may indicate a new direction for the treatment of IBD and other inflammations in the future.

\section{CypD}

The regulation of CypD on IBD is major related to mitochondrial permeability transition (mPT). In vivo and in vitro studies have shown that the inhibition or targeted deletion of CypD attenuated the mitochondrial necrosis of intestinal epithelial cells [148], macrophages [149] and eosinophils [150] induced by inflammatory stimuli such as non-steroidal anti-inflammatory drugs (NSAID), LPS and $\mathrm{Ca}^{2+}$ or oxidative stress, respectively, thereby regulating enteritis, which is related to the closure of mPTP after CypD deficiency (Figure 2). Interestingly, contrary to the results that CypD knockout or inhibition in macrophages and intestinal epithelial cells reduced inflammation, CypD knockout in eosinophils aggravated colon inflammation in mice. However, this may be related to the different regulatory roles of different target cells in IBD (Figure
2). In summary, the absence of CypD in intestinal epithelial cells, macrophages and eosinophils can protect cells from a series of mitochondrial reactions caused by the continuous opening of $\mathrm{MPTP}$, such as mitochondrial membrane depolarization, increased reactive oxygen species and oxidative stress [66-68], thereby reducing cell death caused by mitochondrial necrosis (Figure 2). However, the decrease in the death of intestinal macrophages and endothelial cells plays a positive role in inflammation, while the decrease in the necrosis of eosinophils aggravates intestinal inflammation. Therefore, the difference in immune cells makes the lack of CypD also two sides for IBD.

\section{Other Cyps}

In addition to CypA and CypD, other Cyps have also been found to play an important role in the development of IBD. CypJ, also known as PPIase-like 3 (PPIL3), is a newly discovered member of the cyclophilin family in recent years. It mainly exists in the cytoplasm and nucleus, and it also has PPIase activity [113]. Previous studies have found that CypJ interacted with the Npl4 zinc finger (NZF) domain of TGF- $\beta$-activated kinase 1 binding protein $2 / 3$ and the components of linear ubiquitin chain assembly complexes, blocking the ubiquitin chain binding, negatively regulating NF-kB signaling, thereby inhibiting DSS-induced colitis [113].

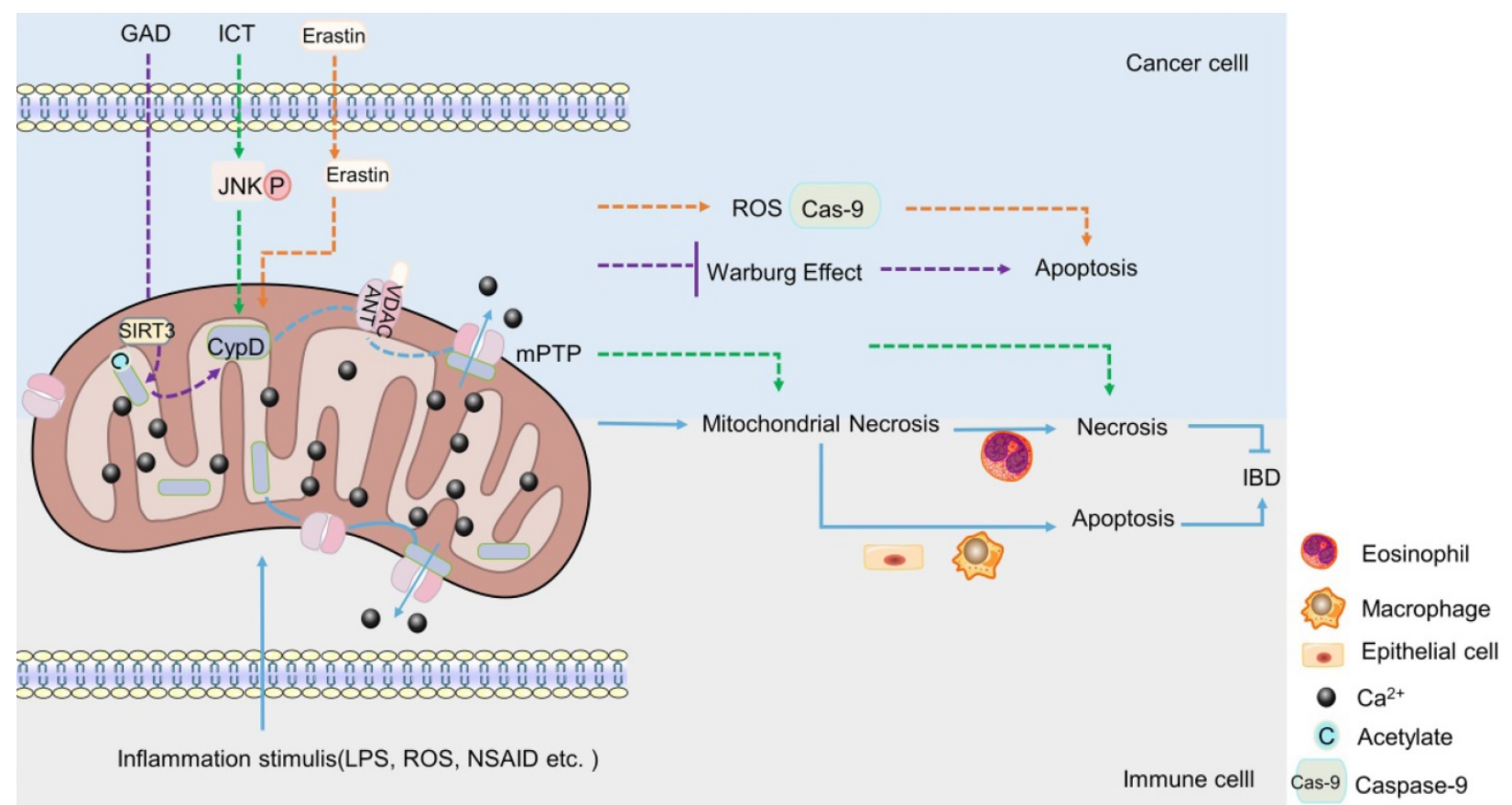

Figure 2. The role of CypD in IBD and CRC. When stimulated by inflammation, CypD travels to the inner membrane and binds to ANT-1, which leads to mPTP sustained opening, $\mathrm{Ca}^{2+}$ outflow, mitochondrial necrosis. The apoptosis of intestinal epithelial cells and macrophages can aggravate IBD, the necrosis of eosinophil can reduce IBD (Lower part). Various drugs or small molecules targeting mPTP can induce apoptosis or necrosis of CRC cells by inducing Warburg changes, necrosis and oxidative stress in mitochondria, respectively (Upper part). 


\section{The relationship between Cyps and colorectal cancer}

\section{Cyps is high expression in CRC}

In many studies, it has been confirmed that the expression of Cyps is significantly different between CRC and normal tissues. Over the years, many researchers have found that CypA [21, 32, 107, 151], СурB [108, 152, 153], СypE [154] and CypJ [155] in CRC tissue were increased expression compared with those in normal tissues or adjacent tissues. Even CypB in the serum of patients [107, 153] and CypA in different CRC cell lines in vitro [107, 153], were found to be overexpressed. Moreover, the high level of CypB has been confirmed to be related to the poor prognosis and low survival rate of patients [108, 152, 153]. Some studies also found that the high expression of CypA in colon cancer was accompanied by the up-regulation of CD147 expression, and the expression changes of the two were consistent. It is suggest that CD147 may be positively correlated with the over-expressed of CypA in colon cancer tissues, which provides clues for further exploring the mechanism of CypA in CRC. In summary, compared with non-cancerous tissues, the expression of Cyps in CRC is generally up-regulated, suggesting that the expression of Cyps may be related to the occurrence of CRC.

Besides the markedly high expression of Cyps in CRC, the expression of Cyps is closely correlated with the progression of CRC. The expression of Cyps increased with the decrease of CRC differentiation, the occurrence of lymph node metastasis [21, 156], TNM (tumor, node, metastases) stage and tumor invasion [109, 155]. Consistent with these experimental results, in addition to the direct study of CRC patients with pathological tissues, there were also through the establishment of early submucosal non-invasive and invasive CRC rat tumor model, proteomics analysis found that compared with non-invasive CRC and normal control group, invasive CRC CypA protein expression increased significantly [157]. Interestingly, Yeonghwan Kim's team also studied the relationship between СурВ expression and tumor progression, but did not find any relevance between CypB overexpression and the grade or development of colon cancer [152], which seems to be in contradiction with the previous researches that found the expression of CypB in CRC with lymph node metastasis was significantly increased [156]. Yeonghwan Kim et al. [37] believed that it was related to the fact that CypB was mainly distributed in ER, and its expression might be mainly affected by ER oxidative stress rather than tumor invasion and metastasis. Urgently, the expression level of CypB in the progression of CRC needs more experiments to illustrate, but clearly, these results can be confirmed that the general high expression of Cyps may be closely related to the occurrence, development and metastasis of CRC.

\section{The possible mechanisms of Cyps in CRC}

In addition to its high expression in CRC, different members of Cyps can participate in the development of CRC in different ways. The mechanism of Cyps in CRC will be briefly reviewed in the form of family members.

\section{CypA}

The role of CypA in CRC generally focuses on the proliferation, invasion and metastasis of cancer cells. The effect of eCypA on CRC is also closely related to the signal regulation of CD147 receptor. The combination of eCypA and CD147 on cell membrane activated downstream pathways through ERK1/2 $[122,158]$, and the activation of MAPK promoted tumor metastasis [34] (Figure 3). It is speculate that eCypA may play a role in the proliferation and metastasis of CRC by binding to CD147 and regulating the downstream MAPK signaling pathway. Meanwhile, a number of experiments have shown that the regulation of MMPs in tumors was controlled by the activation of the p38MAPK signal [159-162], and played an important role in promoting the invasion and metastasis of cancer cells [35, 159-162]. Consistently, recent studies found that the activity of MMP-9 promoter was markedly enhanced in CRC [163] (Figure 3). In summary, it can be speculated that the combination of eCypA and CD147 may also regulate the expression of MMPs through the MAPK signaling pathway, which has a certain effect on the invasion and metastasis of CRC or other cancer cells (Figure 3 ).

Apart from eCypA, the inhibition or knockout of iCypA also affected the proliferation, migration and invasion of CRC. Early studies discovered that sanglifehrin A (SFA, one kind of immunosuppressor) inhibited the proliferation of macrophages through iCypA [124]. Similarly, SFA was also found to inhibit the proliferation of human colon cancer cell HCT-116 after binding to iCypA [164]. However, unlike the inhibition of ERK1/2 activity in macrophages (Figure 1) [124], SFA activated NF-kB signal after inhibiting iCypA in colon cancer cells. Subsequently, NF-kB promoted the transcription of tumor suppressor gene p53 in cancer cells, stimulated the increase of p21 expression, and inhibited the activity of cyclinE-CDK2, thereby inhibiting the proliferation of colon cancer cells [164] (Figure 3). Based on the results mentioned above, it is suggest that the inhibition of 
iCypA not only negatively regulates the migration and proliferation of immune cells [124], but also relates to the inhibition of CRC cell proliferation [164]. However, the difference may be that iCypA has different effects on CRC cells and immune cells such as macrophages (Figure 1 and 3).

Nevertheless, in a recent study to explore the effect of CypA on the progression of colon cancer [165], the invasion and metastasis of SW480 cells were significantly inhibited after the iCypA gene was knocked out, but there was no effect on cell proliferation (Figure 3). Simultaneously, there was up-regulation of E-cadherin (regulating the epithelial properties of cells) and down-regulation of $\mathrm{N}$-cadherin (regulating the mesenchymal properties of cells) [165], indicating that iCypA may promote the invasion and metastasis of colon cancer cells by regulating epithelial mesenchymal transition (EMT). It is worth mentioning that, similar to the phosphorylation of NF-kB signal induced by the inhibition of iCypA [164], the knockout of iCypA also caused the activation of p38MAPK (Figure 3). And the use of p38 inhibitors increased the invasion number of iCypA knockout colon cancer cells [165], which once again proves the previous conjecture that the inhibition or knockout of iCypA in CRC cells may promote the activation of NF-kB and MAPK signals. But, it may have the opposite effect in immune cells. Interestingly, the expression and release of MMPs involved in cell invasion were also examined. However, these MMPs did not change after iCypA knockout, even lowered than the detection limit [165] (Figure 3). This seems to be in contradiction with many experimental results indicating that the activation of MAPK promotes the expression of MMPs [34, 121, 134-136], but this suggests that eCypA and iCypA may have different effects on MAPK in different cancer cells (Figure 3). Additionally, the expression of MMPs cannot exclude the possibility of other signal pathway regulation, which needs further study. But it is certain that CypA does play an important role in the invasion and metastasis of CRC.

\section{CypB}

In cancer biology, СypB is associated with the malignant progression and regulation of a variety of tumors [166-171], but its research in CRC is rarely reported.

In the last decade, Sung Soo Kim et al. have been devoted to the study of CypB [108, 152, 172]. In 2011, they first studied the induction of $\mathrm{CypB}$ under hypoxia and its function in tumor cells in vivo and in vitro [152]. Their sesults showed that $\mathrm{CypB}$ regulated angiogenesis though hypoxia inducible factor-1a (HIF-1a)-mediated vascular endothelial growth factor (VEGF), and protected tumor cells including liver cancer and colon cancer cells from stress-induced apoptosis, including hypoxia and cisplatin-induced stress [152] (Figure 4). These results suggest that СурВ may be a new candidate target for the development of anti- hepatocarcinoma and colon cancer, which also lays a certain foundation for subsequent researches of

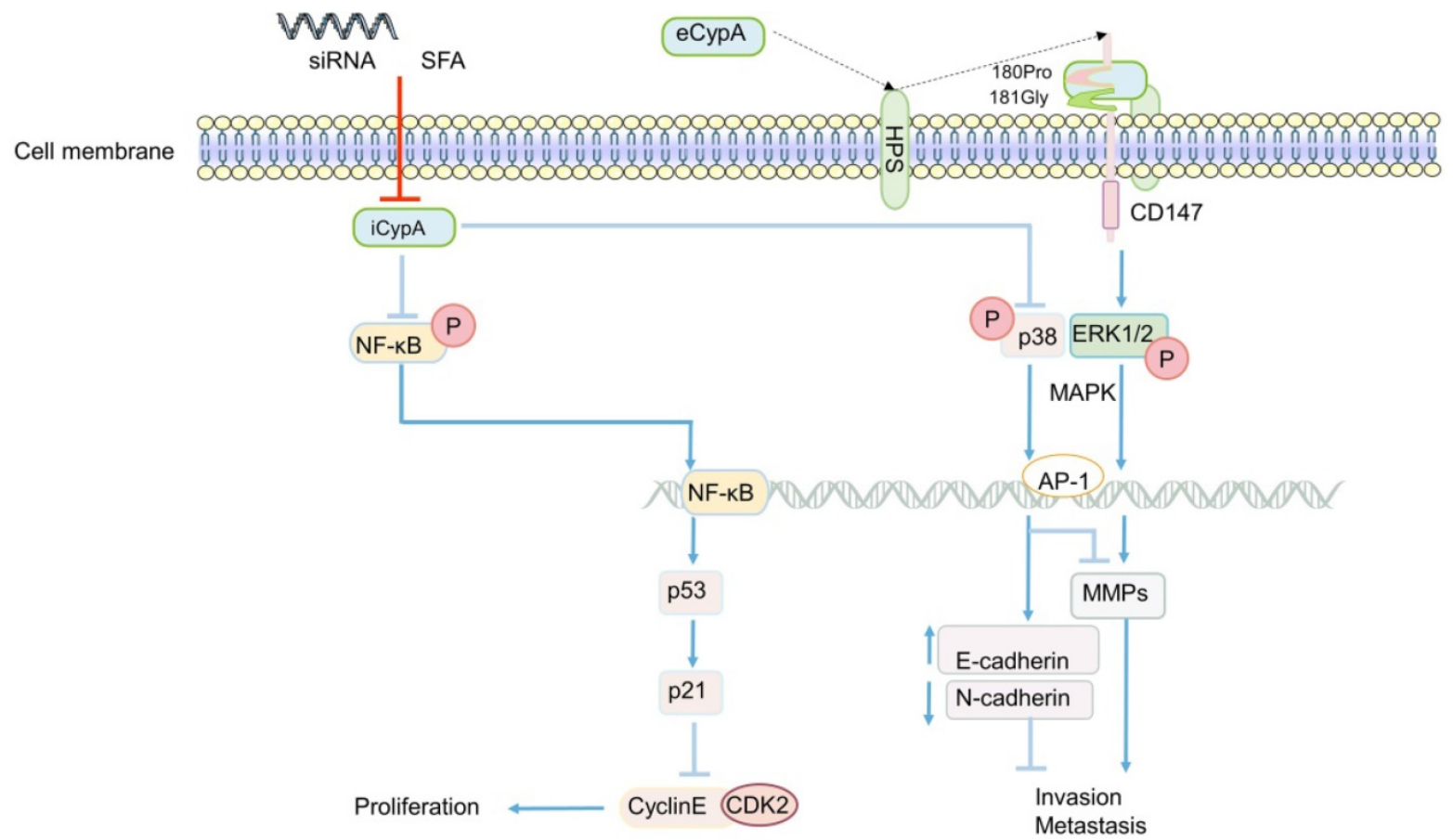

Figure 3. The regulatory role of CypA in CRC. eCypA and iCypA have different effects on NF-KB and MAPK pathways. Both iCypA and eCypA can respectively regulate CyclinE-CDK2, EMT and MMPs through these two signaling pathways, which have different effects on CRC. 
CypB in chemotherapy resistance of CRC patients. However, in this study, the relevant mechanism of hypoxia-induced up-regulation of CypB expression was not deeply explored. In 2015, they demonstrated for the first time that hypoxia up-regulated the transcription of $\mathrm{CypB}$ by activating transcription factor 6 (ATF-6) [172], thus elucidating the mechanism relatively completely. In recent years, they began to study the mechanism of СурB regulating chemoresistance in CRC [108]. The results showed that tumor suppressor gene p53 wild-type (p53WT) up-regulated the mRNA and protein levels of CypB, and overexpressed CypB interacted with ubiquitin E3 ligase (MDM2), so as to make p53WT ubiquitination degradation and short its half-life, thus inhibiting oxaliplatin-induced apoptosis of CRC cells (Figure 4). On the contrary, СypB knockout prolonged the half-life of p53WT and stimulated apoptosis of cancer cells [108]. These results suggest that СурВ is an effective target for improving chemoresistance in patients with CRC. In conclusion, these experiments suggest that $\mathrm{CypB}$ is regulated by oncogene transcription factors such as HIF-1a, ATF-6 and p53WT, which may be related to ER stress and extensive signaling pathways, and determine the role of CypB in chemotherapy resistance of CRC.

Apart from participating in the regulation of chemoresistance in CRC, CypB was found to play a critical role in the invasion and metastasis of CRC $[153,156]$. CypB was knocked out by RNA interference plasmid in CRC cell, the results showed that the migration and invasion abilities of cancer cells were significantly reduced [156] (Figure 4). However, the specific mechanism of СypB promoting the migration and invasion of cancer cells was not revealed in this study. A recent study showed that СурB silencing reduced the proliferation, invasion and migration of colon cancer in vivo and in vitro by blocking IL-6-induced signal transducer and activator of transcription-3 (STAT3) phosphorylation and nuclear translocation [153] (Figure 4). Besides, СурВ silencing also blocked the hydroxylation of type I collagen and the formation of strip bands, thereby inhibiting the metastasis of cancer cells [153] (Figure 4). In conclusion, STAT3/CypB/collagen regulatory axis may play a crucial role in the development of $\mathrm{CRC}$, and $\mathrm{CypB}$ may be an effective target for preventing the proliferation, invasion and migration of CRC.

\section{CypD}

CypD is a component of mPTP. The role of CypD in $\mathrm{MPTP}$ has been widely used in experiments in recent years. It seems that the effect of CypD on CRC also revolves around cell death induced by $\mathrm{MPTP}$ [173-176]. Some chemotherapeutic drugs have been found to promote the combination of mitochondrial ANT-1 and CypD, reduce the mitochondrial membrane potential, promote the opening of $\mathrm{MPTP}$, and exert a toxic effect on CRC cells through

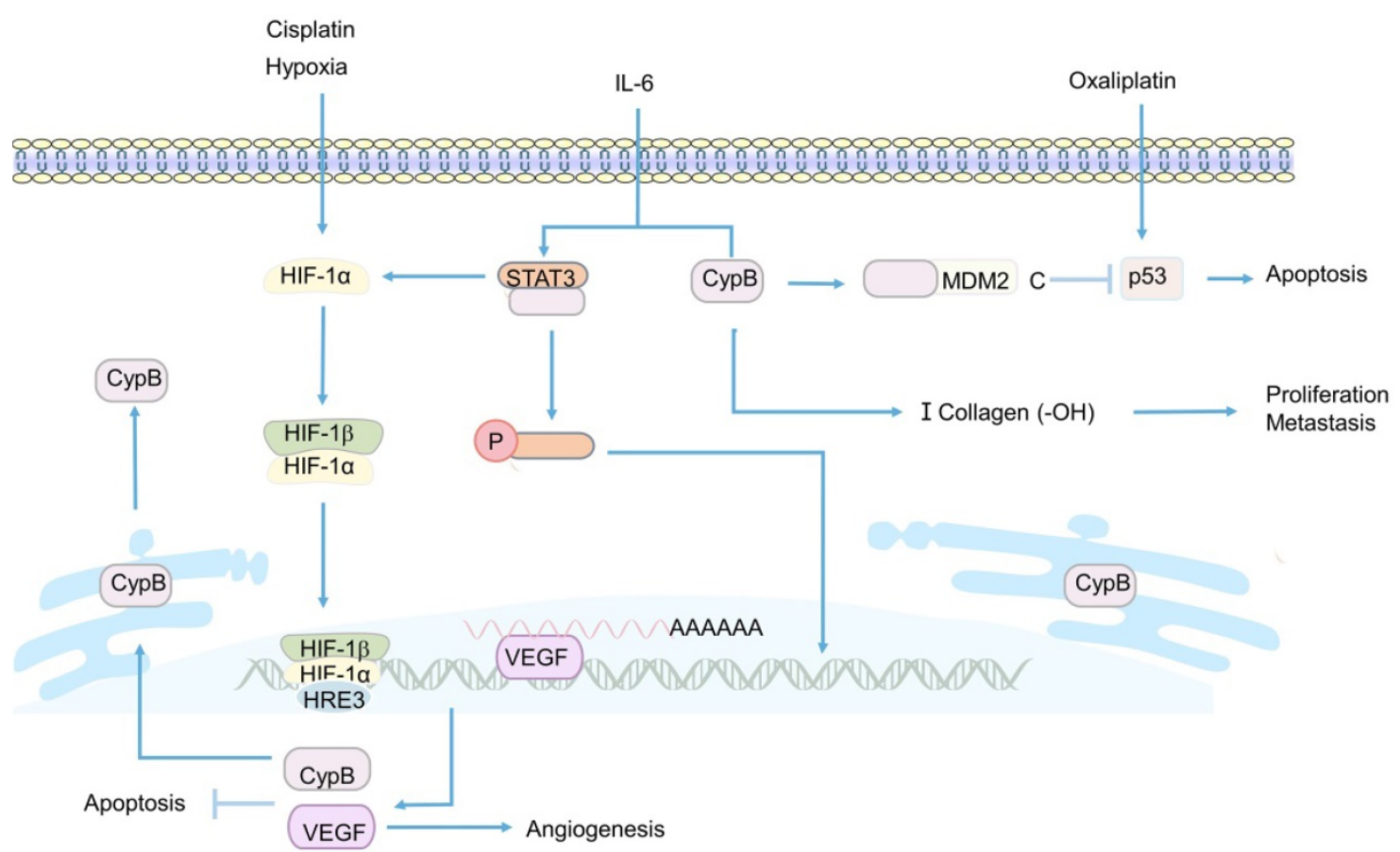

Figure 4. Related mechanisms of CypB involved in CRC. HIF-1 $\alpha$ promotes the transcription and expression of VEGF and CypB, thereby inhibiting hypoxia and cisplatin-induced apoptosis in CRC. Overexpression of CypB can bind to STAT3 and induce its phosphorylation and nuclear transfer in the presence of IL-6, and also positively promotes the transcription of HIF- 1 a and the formation of type I collagen. $\mathrm{p} 53$ upregulates the expression of CypB, the interaction between CypB and $\mathrm{N}$-terminal of MDM 2 can degrade $\mathrm{p} 53$ protein and inhibit oxaliplatin induced apoptosis of $\mathrm{CRCr}$ cells. 
mitochondrial programmed necrosis, inducing necrosis of cancer cells, but not apoptosis (Figure 2). Consistently, the toxicity was significantly attenuated when CypD inhibitors or corresponding siRNA were used [173, 174]. In mouse, after CsA treatment, the inhibitory effect of chemotherapeutic drugs on the growth of HCT-116 xenograft was significantly weakened [174]. Correspondingly, the overexpression of CypD significantly enhanced the sensitivity and cytotoxicity of CRC cells to chemotherapeutic drugs [174]. This indicates that CypD may play an important role in the cytotoxic effects of chemotherapeutic drugs on CRC cells, and this effect is closely related to mitochondrial programmed necrosis. In the study of Chunxian Zhou et al., it was also found that the opening of mPTP stimulated by icariin (ICT, a chemotherapeutic drug), was induced by JNK activation pathway [173], suggesting that JNK signaling pathway may be one of the regulatory mechanisms of CypD involved in chemotherapyinduced CRC cell necrosis (Figure 2).

However, it is interesting that in addition to mitochondrial programmed necrosis, a new anti-cancer drug candidate has been found to induce apoptosis of CRC cells by disrupting mPTP [175]. Erastin was a VDAC-1 binding small molecule that promoted VDAC-1 binding to CypD, cytochrome C release and regulated $\mathrm{MPTP}$ opening, thereby inducing mitochondrial oxidative stress and caspase9-dependent apoptosis to produce cytotoxic effects on various CRC cells (Figure 2). CypD inhibitors significantly attenuated the drug-induced cytotoxicity and apoptosis [175]. This not only indicates the emergence of a potential new drug against CRC, but also suggests that CypD may also be involved in the drug-induced apoptosis of CRC cells by regulating mPTP. To sum up, CypD can participate in the cytotoxic effect of drugs on CRC not only through the necrosis, but also through the apoptosis. The difference of these pathways may be related to the types of drugs, the molecules bound to CypD, and the ways to induce the opening of MPTP.

In a recent study, it was found that Ganoderma acid D (GAD) induced the deacetylation of CypD by up-regulating the level of mitochondrial deacetylase Sirtuin 3 (SIRT3) in a dose-dependent manner, which changed the open state of MPTP, thereby inhibiting the Warburg effect of colon cancer cells and causing cells death [176]. This suggests a possible new way and mechanism for CypD to participate in drugs to inhibit CRC, but the inhibitory effects of different drugs on CRC cells are always related to the involvement of CypD in the regulation of the open state of $\mathrm{mPTP}$.

\section{Summary}

In general, Cyps is highly expressed in IBD and $\mathrm{CRC}$, and even has a certain correlation with the course of disease and prognosis, which suggests that Cyps may be a diagnostic and prognostic indicator. For IBD, Cyps can play a role in inflammation through the secretion of inflammatory factors, apoptosis, autophagy and necrosis of immune cells. In CRC, Cyps is mainly involved in invasion, metastasis, apoptosis, necrosis and drug resistance of cancer cells. The mechanisms of Cyps in these two diseases are generally focus on the signaling molecules such as MAPK, NF-kB and mitochondrial programmed death, and the specific mechanisms remain to be further explored. However, at least it is certain that Cyps will play an important role in the future research on IBD and CRC, and provide effective clues for disease treatment targets or new drug development.

\section{Abbreviations}

CRC: colorectal cancer; IBD: inflammatory bowel disease; Cyps: Cyclophilins; UC: ulcerative colitis; PPIase: peptidyl prolyl isomerase; CsA: Cyclosporin A; NF-AT: nuclear factor of activated T cells; CypA: Cyclophilin A; CypB: Cyclophilin B; CypC: Cyclophilin C; CypD: Cyclophilin D; Cyp40: Cyclophilin 40; CypNK: Cyclophilin NK; iCypA: intracellular CypA; VSMC: vascular smooth muscle cells; EC: endothelial cells; eCypA: extracellular CypA; ER: endoplasmic reticulum; eCypB: extracellular CypB; HIV: human immunodeficiency virus; MPTP: mitochondrial permeability transition pore; VDAC: voltage-dependent anion channel; ANT-1: adenine nucleotide translocator-1; CD: Crohn's disease; CypJ: Cyclophilin J; DSS: Dextransulfatesodium; NF-кB: nuclear factor kappa B; LPS: lipopolysaccharide; CD147: differentiation cluster 147; MMPs: matrix metalloproteinases; TIMP-1: tissue inhibitor of matrix metalloproteinases-1; EMMPRIN: extracellular matrix metalloproteinase inducer; HPS: Heparan sulfates; GAG: Glycosaminoglycans; mPT: mitochondrial permeability transition; NSAID: non-steroidal antiinflammatory drugs; PPIL3: PPIase-like 3; NZF: Npl4 zinc finger; TNM: tumor, node, metastases; SFA: Sanglifehrin A; EMT: epithelial mesenchymal transition; HIF-1a: hypoxia inducible factor-1a; VEGF: vascular endothelial growth factor; ATF-6: activation of transcription factor-6; p53WT: p53 wild-type; MDM2: ubiquitin E3 ligase; STAT-3: signal transducer and activator of transcription-3; ICT: Icariin; GAD: Ganoderma acid D; SIRT3: Sirtuin 3. 


\section{Competing Interests}

The authors have declared that no competing interest exists.

\section{References}

1. Wang P, Heitman J. The cyclophilins. Genome biology. 2005; 6: 226.

2. Takahashi N, Hayano T, Suzuki M. Peptidyl-prolyl cis-trans isomerase is the cyclosporin A-binding protein cyclophilin. Nature. 1989; 337: 473-5.

3. Hoffmann H, Schiene-Fischer C. Functional aspects of extracellular cyclophilins. Biological chemistry. 2014; 395: 721-35.

4. Davis TL, Walker JR, Campagna-Slater V, Finerty PJ, Paramanathan R, Bernstein $G$, et al. Structural and biochemical characterization of the human cyclophilin family of peptidyl-prolyl isomerases. PLoS biology. 2010; 8: e1000439.

5. Liu J, Farmer JD, Lane WS, Friedman J, Weissman I, Schreiber SL. Calcineurin is a common target of cyclophilin-cyclosporin A and FKBP-FK506 complexes. Cell. 1991; 66: 807-15

6. Fischer G, Schmid FX. The mechanism of protein folding. Implications of in vitro refolding models for de novo protein folding and translocation in the cell. Biochemistry. 1990; 29: 2205-12

7. Lee J. Role of cyclophilin a during oncogenesis. Archives of pharmacal research. 2010; 33: 181-7.

8. Hopkins S, Gallay PA. The role of immunophilins in viral infection. Biochimica et biophysica acta. 2015; 1850: 2103-10.

9. Dawar FU, Tu J, Khattak MN, Mei J, Lin L. Cyclophilin A: A Key Factor in Virus Replication and Potential Target for Anti-viral Therapy. Current issues in molecular biology. 2017; 21: 1-20.

10. Xue C, Sowden M, Berk BC. Extracellular Cyclophilin A, Especially Acetylated, Causes Pulmonary Hypertension by Stimulating Endothelial Apoptosis, Redox Stress, and Inflammation. Arteriosclerosis, thrombosis, and vascular biology. 2017; 37: 1138-46.

11. Xue $C$, Senchanthisai S, Sowden M, Pang J, White J, Berk BC. Endothelial-to-Mesenchymal Transition and Inflammation Play Key Roles in Cyclophilin A-Induced Pulmonary Arterial Hypertension. Hypertension. 2020; 76: 1113-23.

12. Leong KG, Ozols E, Kanellis J, Nikolic-Paterson DJ, Ma FY, Cyclophilin A Promotes Inflammation in Acute Kidney Injury but Not in Renal Fibrosis. International journal of molecular sciences. 2020; 21: 3667

13. Wang G, Shen J, Sun J, Jiang Z, Fan J, Wang H, et al. Cyclophilin A Maintains Glioma-Initiating Cell Stemness by Regulating Wnt/beta-Catenin Signaling. Clinical cancer research: an official journal of the American Association for Cancer Research. 2017; 23: 6640-9.

14. Kalagara R, Gao W, Glenn HL, Ziegler C, Belmont L, Meldrum DR. Identification of stable reference genes for lipopolysaccharide-stimulated macrophage gene expression studies. Biology methods \& protocols. 2016; 1: bpw005.

15. Barik S. Immunophilins: for the love of proteins. Cellular and molecular life sciences: CMLS. 2006; 63: 2889-900.

16. Xue C, Sowden MP, Berk BC. Extracellular and Intracellular Cyclophilin A, Native and Post-Translationally Modified, Show Diverse and Specific Pathological Roles in Diseases. Arteriosclerosis, thrombosis, and vascular biology. 2018; 38: 986-93.

17. Jin ZG, Melaragno MG, Liao DF, Yan C, Haendeler I, Suh YA, et al. Cyclophilin $\mathrm{A}$ is a secreted growth factor induced by oxidative stress. Circulation research. 2000; 87: 789-96.

18. Sherry B, Yarlett N, Strupp A, Cerami A. Identification of cyclophilin as a proinflammatory secretory product of lipopolysaccharide-activated macrophages. Proceedings of the National Academy of Sciences of the United States of America. 1992; 89: 3511-5.

19. Bakhanashvili M, Hizi A. A possible role for cysteine residues in the fidelity of DNA synthesis exhibited by the reverse transcriptases of human immunodeficiency viruses type 1 and type 2. FEBS Letters. 1992; 304: 289-93.

20. Suzuki J, Jin Z-G, Meoli DF, Matoba T, Berk BC. Cyclophilin A Is Secreted by a Vesicular Pathway in Vascular Smooth Muscle Cells. Circulation research. 2006; 98: 811-7.

21. Ke P. The Expression and Significance of CD147 and CypA in Colon Cancer [Master]: Central South University; 2007.

22. Kim S-H, Lessner SM, Sakurai Y, Galis ZS. Cyclophilin A as a novel biphasic mediator of endothelial activation and dysfunction. Am J Pathol. 2004; 164: $1567-74$

23. Chao, Xue, Mark, Sowden, Bradford, Berk. Extracellular Cyclophilin A, Especially Acetylated, Causes Pulmonary Hypertension by Stimulating Endothelial Apoptosis, Redox Stress, and Inflammation. Arteriosclerosis, thrombosis, and vascular biology. 2017; 37: 1138-46.

24. Satoh, Kimio. Cyclophilin A in Cardiovascular Homeostasis and Diseases. Tohoku Journal of Experimental Medicine. 2015; 235: 1-15.

25. Doti N, Ruvo M. Relevance and therapeutic potential of CypA targeting to block apoptosis inducing factor-mediated neuronal cell death. Neural regeneration research. 2017; 12: 1428-9.

26. Nigro P, Pompilio G, Capogrossi MC. Cyclophilin A: a key player for human disease. Cell death \& disease. 2013; 4: e888.
27. Seizer $\mathrm{P}$, Ungern-Sternberg SNIV, Schnberger $\mathrm{T}$, Borst $\mathrm{O}$, May $\mathrm{AE}$. Extracellular Cyclophilin A Activates Platelets Via EMMPRIN (CD147) and PI3K/Akt Signaling, Which Promotes Platelet Adhesion and Thrombus Formation In vitro and In vivo. Arteriosclerosis, thrombosis, and vascular biology. 2015; 35: 655-63.

28. Corton JC, Moreno ES, Merritt A, Bocos C, Cattley RC. Cloning genes responsive to a hepatocarcinogenic peroxisome proliferator chemical reveals novel targets of regulation. Cancer Letters. 1998; 134: 61-71.

29. Cecconi D, Astner H, Donadelli M, Palmieri M, Missiaglia E, Hamdan M, et al. Proteomic analysis of pancreatic ductal carcinoma cells treated with 5-aza-2'-deoxycytidine. Electrophoresis. 2003; 24: 4291-303.

30. Yang H, Chen J, Yang J, Qiao S, Zhao S, Yu L. Cyclophilin A is upregulated in small cell lung cancer and activates ERK1/2 signal. Biochemical and biophysical research communications. 2007; 361: 763-7.

31. Zheng J, Koblinski JE, Dutson LV, Feeney YB, Clevenger CV. Prolyl Isomerase Cyclophilin A Regulation of Janus-Activated Kinase 2 and the Progression of Human Breast Cancer. Cancer Research. 2008; 68: 7769-78.

32. Melle C, Osterloh D, Ernst G, Schimmel B, Bleul A, Von Eggeling F. Identification of proteins from colorectal cancer tissue by two-dimensional gel electrophoresis and SELDI mass spectrometry. International Journal of Molecular Medicine. 2005; 16: 11-7.

33. Qi YJ, He QY, Ma YF, Du YW, Liu GC, Li YJ, et al. Proteomic identification of malignant transformation-related proteins in esophageal squamous cell carcinoma. Journal of cellular biochemistry. 2008; 104: 1625-35.

34. Guo Y, Jiang M, Zhao X, Gu M, Wang Z, Xu S, et al. Cyclophilin A promotes non-small cell lung cancer metastasis via p38 MAPK. Thoracic Cancer. 2018; 9 : 120-8.

35. Zhang M, Dai C, Zhu H, Chen S, Wu Y, Li Q, et al. Cyclophilin A promotes human hepatocellular carcinoma cell metastasis via regulation of MMP3 and MMP9. Molecular and cellular biochemistry. 2011; 357: 387-95.

36. Feng MX, Li JP, Wang $\mathrm{H}$, Shen YX, Tan LJ, Wang $\mathrm{Q}$, et al. Clinical significance of cyclophilin a expression in esophageal squamous cell carcinoma. Genetic testing and molecular biomarkers. 2015; 19: 182-6.

37. Kim J, Choi TG, Ding Y, Kim Y, Ha KS, Lee KH, et al. Overexpressed cyclophilin B suppresses apoptosis associated with ROS and Ca2+ homeostasis after ER stress. Journal of cell science. 2008; 121: 3636-48.

38. Spik G, Haendler B, Delmas O, Mariller C, Chamoux M, Maes P, et al. A novel secreted cyclophilin-like protein (SCYLP). The Journal of biological chemistry. 1991; 266: 10735-8.

39. Allain F, Boutillon C, Mariller C, Spik G. Selective assay for CyPA and CyPB in human blood using highly specific anti-peptide antibodies. J Immunol Methods. 1995; 178: 113-20.

40. Arber S, Krause KH, Caroni P. s-cyclophilin is retained intracellularly via a unique $\mathrm{COOH}$-terminal sequence and colocalizes with the calcium storage protein calreticulin. J Cell Biol. 1992; 116: 113-25.

41. Price ER, Zydowsky LD, Jin MJ, Baker CH, McKeon FD, Walsh CT. Human cyclophilin B: a second cyclophilin gene encodes a peptidyl-prolyl isomerase with a signal sequence. Proceedings of the National Academy of Sciences of the United States of America. 1991; 88: 1903-7.

42. Obata Y, Yamamoto K, Miyazaki M, Shimotohno K, Kohno S, Matsuyama T. Role of cyclophilin B in activation of interferon regulatory factor-3. The Journal of biological chemistry. 2005; 280: 18355-60.

43. Rycyzyn MA, Clevenger CV. The intranuclear prolactin/cyclophilin B complex as a transcriptional inducer. Proceedings of the National Academy of Sciences of the United States of America. 2002; 99: 6790-5.

44. Bukrinsky MI. Cyclophilins: unexpected messengers in intercellular communications. Trends in Immunology. 2002; 23: 323-5.

45. Rycyzyn MA, Reilly SC, O'Malley K, Clevenger CV. Role of cyclophilin B in prolactin signal transduction and nuclear retrotranslocation. Molecular endocrinology. 2000; 14: 1175-86.

46. Pakula R, Melchior A, Denys A, Vanpouille C, Mazurier J, Allain F. Syndecan-1/CD147 association is essential for cyclophilin B-induced activation of $\mathrm{p} 44 / 42$ mitogen-activated protein kinases and promotion of cell adhesion and chemotaxis. Glycobiology. 2007; 17: 492-503.

47. Marcant A, Denys A, Melchior A, Martinez P, Deligny A, Carpentier M, et al. Cyclophilin B attenuates the expression of TNF-alpha in lipopolysaccharide-stimulated macrophages through the induction of B cell lymphoma-3. Journal of immunology. 2012; 189: 2023-32.

48. Watashi $\mathrm{K}$, Ishii $\mathrm{N}$, Hijikata $\mathrm{M}$, Inoue $\mathrm{D}$, Murata $\mathrm{T}$, Miyanari $\mathrm{Y}$, et al Cyclophilin B Is a Functional Regulator of Hepatitis C Virus RNA Polymerase. Molecular Cell. 2005; 19: 111-22.

49. Inoue $\mathrm{K}$, Umehara $\mathrm{T}$, Ruegg UT, Yasui $\mathrm{F}$, Watanabe $\mathrm{T}$, Yasuda $\mathrm{H}$, et al. Evaluation of a cyclophilin inhibitor in hepatitis $\mathrm{C}$ virus-infected chimeric mice in vivo. Hepatology. 2007; 45: 921-8.

50. Hanoulle $\mathrm{X}$, Badillo A, Wieruszeski JM, Verdegem D, Landrieu I, Bartenschlager R, et al. Hepatitis C virus NS5A protein is a substrate for the peptidyl-prolyl cis/trans isomerase activity of cyclophilins $\mathrm{A}$ and $\mathrm{B}$. The Journal of biological chemistry. 2009; 284: 13589-601.

51. Nag A, Robotham JM, Tang H. Suppression of Viral RNA Binding and the Assembly of Infectious Hepatitis C Virus Particles In vitro by Cyclophilin Inhibitors. Journal of Virology. 2012; 86: 12616-24.

52. Wang $Y$, Zhou X, Debing Y, Chen K, Van Der Laan LJ, Neyts J, et al. Calcineurin inhibitors stimulate and mycophenolic acid inhibits replication of hepatitis E virus. Gastroenterology. 2014; 146: 1775-83. 
53. DeBoer J, Madson CJ, Belshan M. Cyclophilin B enhances HIV-1 infection. Virology. 2016; 489: 282-91.

54. Fang F, Flegler AJ, Du P, Lin S, Clevenger CV. Expression of Cyclophilin B is Associated with Malignant Progression and Regulation of Genes Implicated in the Pathogenesis of Breast Cancer. Am J Pathol. 2009; 174: 297-308.

55. Choi JW, Schroeder MA, Sarkaria JN, Bram RJ. Cyclophilin B supports Myc and mutant p53-dependent survival of glioblastoma multiforme cells. Cancer Res. 2014; 74: 484-96.

56. Ray P, Rialon-Guevara KL, Veras E, Sullenger BA, White RR. Comparing human pancreatic cell secretomes by in vitro aptamer selection identifies cyclophilin B as a candidate pancreatic cancer biomarker. Journal of Clinical Investigation. 2012; 122: 1734-41.

57. Kim K, Kim H, Jeong K, Jung MH, Hahn BS, Yoon KS, et al. Correction to: Release of overexpressed CypB activates ERK signaling through CD147 binding for hepatoma cell resistance to oxidative stress. Apoptosis: an international journal on programmed cell death. 2018; 23: 707-9.

58. Li T, Guo $\mathrm{H}$, Zhao X, Jin J, Zhang L, Li H, et al. Gastric Cancer Cell Proliferation and Survival Is Enabled by a Cyclophilin B/STAT3/miR-520d-5p Signaling Feedback Loop. Cancer Res. 2017; 77: 1227-40.

59. Meng DQ, Li PL, Xie M. Expression and role of cyclophilin B in stomach cancer. Genetics and molecular research: GMR. 2015; 14: 5346-54.

60. Basso E, Fante L, Fowlkes J, Petronilli V, Forte MA, Bernardi P. Properties of the permeability transition pore in mitochondria devoid of Cyclophilin D. The Journal of biological chemistry. 2005; 280: 18558-61.

61. Elrod JW, Molkentin JD. Physiologic functions of cyclophilin D and the mitochondrial permeability transition pore. Circulation journal: official journal of the Japanese Circulation Society. 2013; 77: 1111-22.

62. Halestrap AP, McStay GP, Clarke SJ. The permeability transition pore complex: another view. Biochimie. 2002; 84: 153-66.

63. Halestrap AP. Calcium, mitochondria and reperfusion injury: a pore way to die. Biochemical Society transactions. 2006; 34: 232-7.

64. Hausenloy DJ, Lim SY, Ong SG, Davidson SM, Yellon DM. Mitochondrial cyclophilin-D as a critical mediator of ischaemic preconditioning. Cardiovascular research. 2010; 88: 67-74.

65. Ji C, Yang B, Yang Z, Tu Y, Yang YL, He L, et al. Ultra-violet B (UVB)-induced skin cell death occurs through a cyclophilin D intrinsic signaling pathway. Biochemical and biophysical research communications. 2012; 425: 825-9.

66. Chen B, Xu M, Zhang H, Wang JX, Zheng P, Gong L, et al. Cisplatin-induced non-apoptotic death of pancreatic cancer cells requires mitochondrial cyclophilin-D-p53 signaling. Biochemical and biophysical research communications. 2013; 437: 526-31.

67. Chen SH, Li DL, Yang F, Wu Z, Zhao YY, Jiang Y. Gemcitabine-induced pancreatic cancer cell death is associated with MST1/cyclophilin D mitochondrial complexation. Biochimie. 2014; 103: 71-9.

68. Zhao LP, Ji C, Lu PH, Li C, Xu B, Gao H. Oxygen glucose deprivation (OGD)/re-oxygenation-induced in vitro neuronal cell death involves mitochondrial cyclophilin-D/P53 signaling axis. Neurochemical research. 2013; 38: 705-13.

69. Javadov S, Kuznetsov A. Mitochondrial permeability transition and cell death: the role of cyclophilin d. Frontiers in physiology. 2013; 4: 76

70. Tsujimoto Y, Shimizu S. Role of the mitochondrial membrane permeability transition in cell death. Apoptosis: an international journal on programmed cell death. 2007; 12: 835-40.

71. Vaseva AV, Marchenko ND, Ji K, Tsirka SE, Holzmann S, Moll UM. p53 opens the mitochondrial permeability transition pore to trigger necrosis. Cell. 2012; 149: 1536-48.

72. Wang DZ, Jones AW, Wang WZ, Wang M, Korthuis RJ. Soluble guanylate cyclase activation during ischemic injury in mice protects against postischemic inflammation at the mitochondrial level. American journal of physiology Gastrointestinal and liver physiology. 2016; 310: G747-56

73. Wu PK, Hong SK, Starenki D, Oshima K, Shao H, Gestwicki JE, et al. Mortalin/HSPA9 targeting selectively induces KRAS tumor cell death by perturbing mitochondrial membrane permeability. Oncogene. 2020; 39: 4257-70

74. Kaplan GG, Bernstein CN, Coward S, Bitton A, Murthy SK, Nguyen GC, et al. The Impact of Inflammatory Bowel Disease in Canada 2018: Epidemiology. J Can Assoc Gastroenterol. 2019; 2: :S6-S16.

75. Park SJ, Kim WH, Cheon JH. Clinical characteristics and treatment of inflammatory bowel disease: a comparison of Eastern and Western perspectives. World J Gastroenterol. 2014; 20: 11525-37.

76. Ng SC, Tang W, Ching JY, Wong M, Chow CM, Hui AJ, et al. Incidence and phenotype of inflammatory bowel disease based on results from the Asia-pacific Crohn's and colitis epidemiology study. Gastroenterology. 2013; 145: 158-165

77. Yamamoto-Furusho JK, Sarmiento-Aguilar A, Toledo-Mauriño JJ, Bozada-Gutiérrez KE, Bosques-Padilla FJ, Martínez-Vázquez MA, et al. Incidence and prevalence of inflammatory bowel disease in Mexico from a nationwide cohort study in a period of 15 years (2000-2017). Medicine (Baltimore). 2019; 98: e16291.

78. Coward S, Clement F, Benchimol EI, Bernstein CN, Avina-Zubieta JA, Bitton A, et al. Past and Future Burden of Inflammatory Bowel Diseases Based on Modeling of Population-Based Data. Gastroenterology. 2019; 156: 1345-53.

79. Weimers P, Munkholm P. The Natural History of IBD: Lessons Learned. Curr Treat Options Gastroenterol. 2018; 16: 101-11.
80. Wanderås $\mathrm{MH}$, Moum BA, Høivik ML, Hovde $\varnothing$. Predictive factors for a severe clinical course in ulcerative colitis: Results from population-based studies. World J Gastrointest Pharmacol Ther. 2016; 7: 235-41.

81. Ananthakrishnan AN, Kaplan GG, Ng SC. Changing Global Epidemiology of Inflammatory Bowel Diseases: Sustaining Health Care Delivery Into the 21st Century. Clin Gastroenterol Hepatol. 2020; 18: 1252-60.

82. Zhao M, Gönczi L, Lakatos PL, Burisch J. The burden of inflammatory bowel disease in Europe in 2020. Journal of Crohn's \& colitis. 2021; jjab029.

83. Cao SS. Endoplasmic reticulum stress and unfolded protein response in inflammatory bowel disease. Inflammatory bowel diseases. 2015; $21: 636-44$.

84. Khor B, Gardet A, Xavier RJ. Genetics and pathogenesis of inflammatory bowel disease. Nature. 2011; 474: 307-17.

85. Vatn MH, Sandvik AK. Inflammatory bowel disease. Scandinavian journal of gastroenterology. 2015; 50: 748-62.

86. Hodson R. Inflammatory bowel disease. Nature. 2016; 540: S97.

87. Guan Q. A Comprehensive Review and Update on the Pathogenesis of Inflammatory Bowel Disease. J Immunol Res. 2019; 2019: 7247238.

88. Sakamoto $\mathrm{Y}$, Hiromatsu $\mathrm{K}$, Ishiwata $\mathrm{K}$, Inagaki-Ohara $\mathrm{K}$, Ikeda $\mathrm{T}$, Nakamura-Uchiyama F, et al. Chronic intestinal nematode infection induces Stat6-independent interleukin-5 production and causes eosinophilic inflammatory responses in mice. Immunology. 2004; 112: 615-23.

89. Gajendran M, Loganathan P, Jimenez G, Catinella AP, Ng N, Umapathy C, et al. A comprehensive review and update on ulcerative colitis. Dis Mon. 2019; 65: 100851.

90. Cho E-j, Shin J-S, Noh Y-S, Cho Y-W, Hong S-J, Park J-H, et al. Anti-inflammatory effects of methanol extract of Patrinia scabiosaefolia in mice with ulcerative colitis. J Ethnopharmacol. 2011; 136: 428-35.

91. Yamamoto S, Ma X. Role of Nod2 in the development of Crohn's disease. Microbes Infect. 2009; 11: 912-8.

92. Gajendran M, Loganathan P, Catinella AP, Hashash JG. A comprehensive review and update on Crohn's disease. Dis Mon. 2018; 64: 20-57.

93. Molodecky NA, Soon IS, Rabi DM, Ghali WA, Ferris M, Chernoff G, et al. Increasing incidence and prevalence of the inflammatory bowel diseases with time, based on systematic review. Gastroenterology. 2012; 142: 46-54

94. Ng SC, Shi HY, Hamidi N, Underwood FE, Tang W, Benchimol EI, et al. Worldwide incidence and prevalence of inflammatory bowel disease in the 21st century: a systematic review of population-based studies. Lancet. 2017; 390: $2769-78$

95. Biancone L, Armuzzi A, Scribano ML, D'Inca R, Castiglione F, Papi C, et al. Inflammatory Bowel Disease Phenotype as Risk Factor for Cancer in a Prospective Multicentre Nested Case-Control IG-IBD Study. Journal of Crohn's \& colitis. 2016; 10: 913-24

96. Burisch J, Munkholm P. The epidemiology of inflammatory bowel disease. Scandinavian Journal of Gastroenterology. 2015; 50: 942-51.

97. Danese S, Fiorino G, Peyrin-Biroulet L. Early intervention in Crohn's disease: towards disease modification trials. Gut. 2017; 66: 2179-87.

98. Maaike V, Tim V, Ricard F, Sare V, Marc F, Gert VA, et al. Genetic and Transcriptomic Bases of Intestinal Epithelial Barrier Dysfunction in Inflammatory Bowel Disease. Inflammatory bowel diseases. 2017; 23: 1718-29.

99. Cerf LM, Jan D. Immunoregulatory Role of Myeloid-derived Cells in Inflammatory Bowel Disease. Inflammatory bowel diseases. 2015; 21: 2936-47.

100. Colangelo T, Polcaro G, Muccillo L, D'Agostino G, Rosato V, Ziccardi P, et al. Friend or foe?: The tumour microenvironment dilemma in colorectal cancer. Biochimica et Biophysica Acta (BBA) - Reviews on Cancer. 2017; 1867: 1-18.

101. Schmoll HJ, Stein A. Colorectal cancer in 2013: Towards improved drugs, combinations and patient selection. Nature reviews Clinical oncology. 2014; 11: 79-80.

102. Kuipers EJ, Rosch T, Bretthauer M. Colorectal cancer screening--optimizing current strategies and new directions. Nature reviews Clinical oncology. 2013; 10: $130-42$

103. Brouquet A, Nordlinger B. Metastatic colorectal cancer outcome and fatty liver disease. Nature Reviews Gastroenterology \& Hepatology. 2013; 10: 266-7.

104. Cao W, Chen H-D, Yu Y-W, Li N, Chen W-Q. Changing profiles of cancer burden worldwide and in China: a secondary analysis of the global cancer statistics 2020. Chin Med J (Engl). 2021.

105. Center MM, Jemal A, Smith RA, Ward E. Worldwide variations in colorectal cancer. CA: a cancer journal for clinicians. 2009; 59: 366-78

106. Siegel R, Ma J, Zou Z, Jemal A. Cancer statistics, 2014. CA: a cancer journal for clinicians. 2014; 64: 9-29.

107. Yamamoto T, Kudo M, Peng WX, Takata H, Takakura H, Teduka K, et al. Identification of aldolase A as a potential diagnostic biomarker for colorectal cancer based on proteomic analysis using formalin-fixed paraffin-embedded tissue. Tumour biology: the journal of the International Society for Oncodevelopmental Biology and Medicine. 2016; 37: 13595-606.

108. Choi TG, Nguyen MN, Kim J, Jo YH, Jang M, Nguyen NNY, et al. Cyclophilin $\mathrm{B}$ induces chemoresistance by degrading wild-type $\mathrm{p} 53$ via interaction with MDM2 in colorectal cancer. The Journal of pathology. 2018; 246: 115-26.

109. Peng Y, Li X, Wu M, Yang J, Liu M, Zhang W, et al. New prognosis biomarkers identified by dynamic proteomic analysis of colorectal cancer. Molecular bioSystems. 2012; 8: 3077-88.

110. Piechota-Polanczyk A, Wlodarczyk M, Sobolewska-Wlodarczyk A, Jonakowski M, Pilarczyk A, Stec-Michalska K, et al. Serum Cyclophilin A Correlates with Increased Tissue MMP-9 in Patients with Ulcerative Colitis, but Not with Crohn's Disease. Digestive diseases and sciences. 2017; 62: $1511-7$. 
111. Jianwu Z, Yuzheng Z, Wei Y, Chenggong Y, Xiaoping Z, Yulin W. Correlation Between Cyclophile A and its Autoantibodies and Ulcerative Colitis. Journal of Bengbu Medical College. 2010; 35: 990-2.

112. Jianwu Z, Yuzheng Z, Wei Y, Chenggong Y, Xiaoping Z, Yulin W. Significance of Detection of Serum Cyclophilin A Antibodies in Patients with Ulcerative Colitis. Hainan Medicine. 2010; 21: 4-6.

113. Sheng C, Yao C, Wang Z, Chen H, Zhao Y, Xu D, et al. Cyclophilin J limits inflammation through the blockage of ubiquitin chain sensing. Nature communications. 2018; 9: 4381.

114. Kim M, Lee S, Yang S-K, Song K, Lee I. Differential expression in histologically normal crypts of ulcerative colitis suggests primary crypt disorder. Oncology Reports. 2006; 16: 663-70.

115. Kim J-Y, Kim W-J, Kim H, Suk K, Lee W-H. The Stimulation of CD147 Induces MMP-9 Expression through ERK and NF-kB in Macrophages: Implication for Atherosclerosis. Immune Network. 2009; 9: 90-7.

116. Lu G, Jia Z, Zu Q, Zhang J, Zhao L, Shi H. Inhibition of the cyclophilin A-CD147 interaction attenuates right ventricular injury and dysfunction after acute pulmonary embolism in rats. The Journal of biological chemistry. 2018; 293: 12199-208.

117. Li W, Liu W, Chen C, Fan W, Zhang H, Liu W, et al. [Effect of extracellular cyclophilin A on inflammatory response and anti-inflammatory activity of antibody against cyclophilin A]. Sheng wu gong cheng xue bao = Chinese journal of biotechnology. 2018; 34: 90-101.

118. Dongsheng Z, Zhiguang F, Junfeng J, Zifan L, Li W. Cyclophilin A Aggravates Collagen-Induced Arthritis via Promoting Classically Activated Macrophages. Inflammation. 2017; 40: 1761-72.

119. Jing L, Zhiqiang X, Fuyu C, Jinchuan Y, Zhongqun W, Wei Y. Effect of CyclophilinA on Autophagy of RAW264.7 Macrophages. Journal of Jiangsu University (Medical Edition). 2017; 027: 229-32.

120. Xue Z, Yuan W, Li J, Zhou H, Xu L, Weng J, et al. Cyclophilin A mediates the ox-LDL-induced activation and apoptosis of macrophages via autophagy. International journal of cardiology. 2017; 230: 142-8.

121. Yuan W, Ge H, He B. Pro-inflammatory activities induced by CyPA-EMMPRIN interaction in monocytes. Atherosclerosis. 2010; 213: 415-21.

122. Yang Y, Lu N, Zhou J, Chen ZN, Zhu P. Cyclophilin A up-regulates MMP-9 expression and adhesion of monocytes/macrophages via CD147 signalling pathway in rheumatoid arthritis. Rheumatology. 2008; 47: 1299-310.

123. Chen T, Guo J, Yang M, Han C, Zhang M, Chen W, et al. Cyclosporin A impairs dendritic cell migration by regulating chemokine receptor expression and inhibiting cyclooxygenase-2 expression. Blood. 2004; 103: 413-21.

124. Sanchez-Tillo E, Wojciechowska M, Comalada M, Farrera C, Lloberas J, Celada A. Cyclophilin A is required for M-CSF-dependent macrophage proliferation. European journal of immunology. 2006; 36: 2515-24.

125. Yurchenko V, Zybarth G, O'Connor M, Dai WW, Franchin G, Hao T, et al. Active site residues of cyclophilin A are crucial for its signaling activity via CD147. The Journal of biological chemistry. 2002; 277: 22959-65.

126. Zhang Z, Yang X, Zhang H, Liu X, Pan S, Li C. The role of extracellular matrix metalloproteinase inducer glycosylation in regulating matrix metalloproteinases in periodontitis. Journal of periodontal research. 2018; 53: 391-402.

127. Verma RP, Hansch C. Matrix metalloproteinases (MMPs): chemical-biological functions and (Q)SARs. Bioorganic \& medicinal chemistry. 2007; 15: 2223-68.

128. Zucker S, Hymowitz M, Rollo EE, Mann R, Conner CE, Cao J, et al. Tumorigenic Potential of Extracellular Matrix Metalloproteinase Inducer. Am J Pathol. 2001; 158: 1921-8.

129. Biswas C, Zhang Y, DeCastro R, Guo H, Nakamura T, Kataoka H, et al. The human tumor cell-derived collagenase stimulatory factor (renamed EMMPRIN) is a member of the immunoglobulin superfamily. Cancer Res. 1995; 55: 434-9.

130. Yurchenko V, O'Connor M, Dai WW, Guo H, Toole B, Sherry B, et al. CD147 is a signaling receptor for cyclophilin $\mathrm{B}$. Biochemical and biophysical research communications. 2001; 288: 786-8.

131. Saphire AC, Bobardt MD, Gallay PA. Host cyclophilin A mediates HIV-1 attachment to target cells via heparans. EMBO J. 1999; 18: 6771-85.

132. Denys A, Allain F, Carpentier M, Spik G. Involvement of two classes of binding sites in the interactions of cyclophilin $\mathrm{B}$ with peripheral blood T-lymphocytes. Biochem J. 1998; 336 (Pt 3): 689-97.

133. Min A, Xiong $\mathrm{H}$, Wang $\mathrm{W}$, Hu X, Wang C, Mao T, et al. CD147 promotes proliferation and migration of oral cancer cells by inhibiting junctions between E-cadherin and beta-catenin. Journal of oral pathology \& medicine: official publication of the International Association of Oral Pathologists and the American Academy of Oral Pathology. 2020; 49:1019-29.

134. Fang F, Li Q, Wu M, Nie C, Xu H, Wang L. CD147 promotes epithelialmesenchymal transition of prostate cancer cells via the Wnt/beta-catenin pathway. Experimental and therapeutic medicine. 2020; 20: 3154-60.

135. Wang SJ, Chao D, Wei W, Nan G, Li JY, Liu FL, et al. CD147 promotes collective invasion through cathepsin B in hepatocellular carcinoma. Journal of experimental \& clinical cancer research: CR. 2020; 39: 145.

136. Liu N, Qi M, Li K, Zeng W, Li J, Yin M, et al. CD147 regulates melanoma metastasis via the NFAT1-MMP-9 pathway. Pigment cell \& melanoma research. 2020; 33: 731-43

137. Xu Z, Liu R, Huang L, Xu Y, Su M, Chen J, et al. CD147 Aggravated Inflammatory Bowel Disease by Triggering NF-B-Mediated Pyroptosis. Biomed Res Int. 2020; 2020: 5341247.
138. Matsuda S, Moriguchi T, Koyasu S, Nishida E. T lymphocyte activation signals for interleukin-2 production involve activation of MKK6-p38 and MKK7-SAPK/JNK signaling pathways sensitive to cyclosporin A. The Journal of biological chemistry. 1998; 273: 12378-82.

139. Mason J, Moore LC. Indirect assessment of renal dysfunction in patients taking cyclosporin A for autoimmune diseases. The British journal of dermatology. 1990; 122 Suppl 36: 79-84.

140. Taler DSJ, Textor SC, Canzanello VJ, Schwartz L. Cyclosporin-Induced Hypertension. Drug Safety. 1999; 20: 437-49.

141. Nabel GJ. A transformed view of cyclosporine. Nature. 1999; 397: 471-2.

142. Landrieu I, Hanoulle X, Bonachera F, Hamel A, Sibille N, Yin Y, et al. Structural basis for the non-immunosuppressive character of the cyclosporin A analogue Debio 025. Biochemistry. 2010; 49: 4679-86.

143. Paeshuyse J, Kaul A, De Clercq E, Rosenwirth B, Dumont JM, Scalfaro P, et al. The non-immunosuppressive cyclosporin DEBIO-025 is a potent inhibitor of hepatitis $C$ virus replication in vitro. Hepatology. 2006; 43: 761-70.

144. Hopkins S, Scorneaux B, Huang Z, Murray MG, Wring S, Smitley C, et al. SCY-635, a novel nonimmunosuppressive analog of cyclosporine that exhibits potent inhibition of hepatitis C virus RNA replication in vitro. Antimicrobial agents and chemotherapy. 2010; 54: 660-72.

145. Bartz SR, Hohenwalter E, Hu MK, Rich DH, Malkovsky M. Inhibition of human immunodeficiency virus replication by nonimmunosuppressive analogs of cyclosporin A. Proceedings of the National Academy of Sciences of the United States of America. 1995; 92: 5381-5.

146. Rosenwirth B, Billich A, Steinkasserer A, Hammerschmid F, Peichl P. Mode of action of SDZ NIM 811, a non-immunosuppressive Cyclosporin A analog with activity against human immunodeficiency virus type 1 (HIV-1). Antiviral Research. 1995; 26: A227.

147. Song T, Yang M, Chen J, Huang L, Yin H, He T, et al. Prognosis of sepsis induced by cecal ligation and puncture in mice improved by anti-Clonorchis Sinensis cyclopholin a antibodies. Parasites \& vectors. 2015; 8: 502.

148. LoGuidice A, Ramirez-Alcantara V, Proli A, Gavillet B, Boelsterli UA. Pharmacologic targeting or genetic deletion of mitochondrial cyclophilin D protects from NSAID-induced small intestinal ulceration in mice. Toxicological sciences: an official journal of the Society of Toxicology. 2010; 118: 276-85.

149. Priber J, Fonai F, Jakus PB, Racz B, Chinopoulos C, Tretter L, et al. Cyclophilin $\mathrm{D}$ disruption attenuates lipopolysaccharide-induced inflammatory response in primary mouse macrophages. Biochemistry and cell biology $=$ Biochimie et biologie cellulaire. 2015; 93: 241-50.

150. Zhu X, Hogan SP, Molkentin JD, Zimmermann N. Cyclophilin D regulates necrosis, but not apoptosis, of murine eosinophils. American journal of physiology Gastrointestinal and liver physiology. 2016; 310: G609-17.

151. Qiao L, Hong X, Li S, He C, Gao S, Wang H. Preparation and application of mouse monoclonal antibodies against human cyclophilin A (CypA). Xi Bao Yu Fen Zi Mian Yi Xue Za Zhi. 2018; 34: 746-51.

152. Kim Y, Jang M, Lim S, Won H, Yoon KS, Park JH, et al. Role of cyclophilin B in tumorigenesis and cisplatin resistance in hepatocellular carcinoma in humans. Hepatology. 2011; 54: 1661-78.

153. Guo H, Li T, Shi Y, Zhuang K, Fan D. Sa1174 CYCLOPHILIN B PROMOTES COLON CANCER PROLIFERATION AND METASTASIS THROUGH STAT3 ACTIVATION AND COLLAGEN HYDROXYLATION. Gastroenterology. 2020; 158: S-299.

154. Laidlaw AM, Copeland B, Ross CM, Hardingham JE. Extent of over-expression of hepatocyte growth factor receptor in colorectal tumours is dependent on the choice of normaliser. Biochemical and biophysical research communications. 2006; 341: 1017-21.

155. Hongbo Z, Jian C, Jinchen H, Xixun W, Rongbao J, Lixin J. Expression and Clinical Significance of CyPJ in Colorectal Cancer Tissues. Chinese Electronic Journal of Colorectal Diseases. 2017; 6: 387-91.

156. Lefei, Minhua Z, Aiguo L, Jianwen L. Expression of CypB in Colorectal Cancer Tissue and its Effect on Cancer Cell Migration and Invasion. Journal of Shanghai Jiaotong University (Medical Edition). 2010; 30: 288-91.

157. Zhang J, Song MQ, Zhu JS, Zhou Z, Chen NW. Identification of differentially-expressed proteins between early submucosal non-invasive and invasive colorectal cancer using 2D-DIGE and mass spectrometry. Int $\mathrm{J}$ Immunopathol Pharmacol. 2011; 24: 849-59.

158. Chen J, Xia S, Yang X, Chen H, Li F, Liu F, et al. Human Cytomegalovirus Encoded miR-US25-1-5p Attenuates CD147/EMMPRIN-Mediated Early Antiviral Response. Viruses. 2017; 9:365.

159. Hsieh MJ, Chen KS, Chiou HL, Hsieh YS. Carbonic anhydrase XII promotes invasion and migration ability of MDA-MB-231 breast cancer cells through the p38 MAPK signaling pathway. European journal of cell biology. 2010; 89: 598-606.

160. Johansson N, Ala-aho R, Uitto V, Grénman R, Fusenig NE, López-Otín C, et al. Expression of collagenase-3 (MMP-13) and collagenase-1 (MMP-1) by transformed keratinocytes is dependent on the activity of p38 mitogenactivated protein kinase. Journal of cell science. 2000; $113 \mathrm{Pt}$ 2: 227-35.

161. Kumar P, Yadav A, Patel SN, Islam M, Pan Q, Merajver SD, et al. Tetrathiomolybdate inhibits head and neck cancer metastasis by decreasing tumor cell motility, invasiveness and by promoting tumor cell anoikis. Molecular cancer. 2010; 9: 206

162. Park SY, Jeong KJ, Panupinthu N, Yu S, Lee J, Han JW, et al. Lysophosphatidic acid augments human hepatocellular carcinoma cell invasion through LPA1 receptor and MMP-9 expression. Oncogene. 2011; 30: 1351-9. 
163. Peng K, Kou L, Yu L, Bai C, Li M, Mo P, et al. Histone Demethylase JMJD2D Interacts With beta-Catenin to Induce Transcription and Activate Colorectal Cancer Cell Proliferation and Tumor Growth in Mice. Gastroenterology. 2019; 156: 1112-26.

164. Zhang, Youn LH, Liu HD, J. O. Inhibition of cell cycle progression by the novel cyclophilin ligand sanglifehrin $\mathrm{A}$ is mediated through the NFkappa B-dependent activation of p53. Journal of Biological Chemistry. 2001; 276: 43534-40.

165. Yamamoto T, Takakura H, Mitamura K, Taga A. Cyclophilin a knokdown inhibits cell migration and invasion through the suppression of epithelialmesenchymal transition in colorectal cancer cells. Biochemical and biophysical research communications. 2020; 526: 55-61.

166. Vollmer S, Kappler V, Kaczor J, Flugel D, Rolvering C, Kato N, et al. Hypoxiainducible factor 1alpha is up-regulated by oncostatin $\mathrm{M}$ and participates in oncostatin M signaling. Hepatology. 2009; 50: 253-60.

167. Urbatsch IL, Sankaran B, Weber J, Senior AE. P-glycoprotein is stably inhibited by vanadate-induced trapping of nucleotide at a single catalytic site. The Journal of biological chemistry. 1995; 270: 19383-90.

168. Siegel DS, Zhang X, Feinman R, Teitz T, Zelenetz A, Richon VM, et al. Hexamethylene bisacetamide induces programmed cell death (apoptosis) and down-regulates BCL-2 expression in human myeloma cells. Proceedings of the National Academy of Sciences of the United States of America. 1998; 95: 162-6.

169. Kallio PJ, Pongratz I, Gradin K, Mcguire J, Poellinger L. Activation of hypoxia-inducible factor 1a: Posttranscriptional regulation and conformational change by recruitment of the Arnt transcription factor. Proceedings of the National Academy of Sciences of the United States of America. 1997; 94:5667-72.

170. Kimura H, Weisz A, Ogura T, Hitomi Y, Kurashima Y, Hashimoto K, et al. Identification of hypoxia-inducible factor 1 ancillary sequence and its function in vascular endothelial growth factor gene induction by hypoxia and nitric oxide. The Journal of biological chemistry. 2001; 276: 2292-8.

171. Kuhlicke J, Frick JS, Morote-Garcia JC, Rosenberger P, Eltzschig HK. Hypoxia inducible factor (HIF)-1 coordinates induction of Toll-like receptors TLR2 and TLR6 during hypoxia. PloS one. 2007; 2: e1364.

172. Jeong K, Kim K, Kim H, Oh Y, Kim SJ, Jo Y, et al. Hypoxia induces cyclophilin B through the activation of transcription factor 6 in gastric adenocarcinoma cells. Oncology letters. 2015; 9: 2854-8.

173. Zhou C, Chen Z, Lu X, Wu H, Yang $\mathrm{Q}$, Xu D. Icaritin activates INK-dependent mPTP necrosis pathway in colorectal cancer cells. Tumour biology: the journal of the International Society for Oncodevelopmental Biology and Medicine. 2016; 37: 3135-44.

174. Ju T, Gao D, Fang ZY. Targeting colorectal cancer cells by a novel sphingosine kinase 1 inhibitor PF-543. Biochemical and biophysical research communications. 2016; 470: 728-34.

175. Huo H, Zhou Z, Oin J, Liu W, Wang B, Gu Y. Erastin Disrupts Mitochondrial Permeability Transition Pore (mPTP) and Induces Apoptotic Death of Colorectal Cancer Cells. PloS one. 2016; 11: e0154605.

176. Liu Z, Li L, Xue B. Effect of ganoderic acid D on colon cancer Warburg effect: Role of SIRT3/cyclophilin D. European journal of pharmacology. 2018; 824: $72-7$ 